\title{
Dietary Value of Artemia Enriched with Various Types of Oil for Larval Striped Knifejaw and Red Sea Bream
}

\author{
Toshio Takeuchi, ${ }^{{ }_{1}}$ Masanori Toyota, ${ }^{* 1,2}$ and Takeshi Watanabe ${ }^{* 1}$ \\ (Received August 12, 1991)
}

\begin{abstract}
Two experiments were conducted to compare the dietary value of Artemia enriched with various types of oil, such as triglycerides (TG), methyl esters (ME), ethyl esters (EE), and free fatty acids (FFA) containing about $43 \%$ of n-3 highly unsaturated fatty acids (n-3HUFA), based on the growth, survival and chemical compositions of larval striped knifejaw and red sea bream.

Both larval striped knifejaw and red sea bream fed on nauplii enriched with TG, ME, and EE for 10 and 14 days showed good results in growth, survival and activity tests. These nauplii contained 4.1-7.1\% $\mathrm{n}-3$ HUFA on a dry basis. The former larvae fed on nauplii without treatment or fed on FFA (1.0-1.7\% n-3HUFA) showed poor feed performances. Incorporation of n-3HUFA into Artemia by emulsified FFA was very low due to coagulation of FFA during enrichment, leading to poor feed performances. Red sea bream fed on newly-hatched nauplii with $1 \% \mathrm{n}$ 3HUFA but without docosahexaenoic acid (DHA) showed a high survival rate, but quite low activity. The concentration of eicosapentaenoic acid (EPA) plus DHA in polar lipids of both species fed on nauplii without enrichment or with FFA was somewhat lower than that of fish fed on nauplii enriched with TG, ME, and EE. The value was highest in fish fed on EE-fed Artemia.

Thus, the dietary value of Artemia to both species was effectively improved by enrichment with $\mathrm{TG}, \mathrm{ME}$, and $\mathrm{EE}$, especially with $\mathrm{EE}$.
\end{abstract}

In the large scale seedling production of marine fish, brine shrimp Artemia have been widely employed as food, while formulated microbound diets are still in limited use. ${ }^{1)}$ To improve the nutritional quality of Artemia from the viewpoint of essential fatty acids (EFA), oils containing a high amount of n-3 highly unsaturated fatty acids (n-3HUFA) have been added to the culture medium of Artemia.

Recently, Izquierdo et al.*3 have suggested that the methyl ester (ME) type of oil has some ill effects not only on rotifers but also on fish larvae fed on them. In a previous paper, ${ }^{2}$ it was shown that ester-type oils were converted to triglycerides (TG) and incorporated into the TG fraction of Artemia, and a maximum incorporation of n-3HUFA was observed in Artemia fed with the ethyl ester (EE) type of oil for $24 \mathrm{~h}$. On the other hand, it was also demonstrated that the free fatty acid (FFA) type of oil was comparatively ineffective for Artemia due to coagula- tion of emulsion during enrichment. These results suggest that nauplii enriched with emulsified TG, ME, and EE for 12-24 h are good food for marine larval fish.

This experiment was conducted to compare the dietary value of Artemia enriched with various types of oil, such as TG, ME, EE, and FFA containing about $43 \%$ of $n-3$ HUFA, based on the growth, survival and chemical compositions of larval striped knifejaw Oplegnathus fasciatus (Experiment I) and red sea bream Pagrus major (Experiment II).

\section{Materials and Methods}

Feeding of Artemia with Various Types of Oil by the Direct Method

Newly-hatched nauplii of Artemia from Utah, USA were stocked into $100 l$ tanks at a density of 20-70 individuals $/ \mathrm{m} l$ and enriched with $100 \mathrm{ml}$ of an emulsion prepared from $5 \mathrm{~m} l$ oil, one raw

*1 Department of Aquatic Biosciences, Tokyo University of Fisheries, Konan, Minato, Tokyo 108, Japan (竹内俊郎, 豊田雅典, 渡㟫 武: 東京水座大学壊源育成学科).

*2 Present Address: Animal Health Research Laboratory, Agro Division, Takeda Chemical Industries, Ltd., Juso-honmachi, Yodogawa, Osaka 532, Japan (武田薬品工業株式会社アグロ事業部動物薬研觉所)

* 3 M. S. Izquierdo, T. Takeuchi, T. Arakawa, C. Kitajima, and T. Watanabe: Oral presentation at the annual meeting of Japan. Soc. Sci. Fish., in Tokyo, April 1988, p. 250. 
egg yolk, $94 \mathrm{~m} /$ seawater, and $30 \mathrm{~g}$ baker's yeast for $22-24 \mathrm{~h}$ in Expt. I, and for 19-24 h in Expt. II. The details of the direct method for enrichment and fatty acid compositions of the experimental oils have been described in the previous paper. ${ }^{2)}$ The FFA-type oil was not used to enrich Artemia in Expt. II.

\section{Feeding of Fish Larvae with Artemia}

Feeding experiments were conducted twice (Expts. I and II) with larval striped knifejaw and red sea bream at the Aquaculture Research Laboratory of Nagasaki Prefectural Institute of Fisheries.

1. Striped knifejaw (Expt. 1). Larval fish of $10.1 \pm 0.8 \mathrm{~mm}$ in total length, which had been reared with S-type rotifers fed on Nannochloropsis and omega-yeast, ${ }^{3)}$ were randomly divided into 10 groups (duplicate experiments) containing 200 fish each in $100 /$ polycarbonate tanks. They were fed respectively with one of five varieties of Artemia for ten days at a water temperature of $26.1-27.3^{\circ} \mathrm{C}$. Seawater and aeration were supplied at $800 \mathrm{ml} / \mathrm{min}$ and $500 \mathrm{~m} / / \mathrm{min}$, respectively.

The feeding rate ranged between $(2-6) \times 10^{5}$ nauplii/tank per day. At the end of the trial 50 fish were subjected to an activity test by holding them out of the water in a scoop net for $10 \mathrm{~s}$, transferring them into a $30 /$ tank, and keeping them there for $24 \mathrm{~h}$ to check the fish's response to the stress. The survival rate was calculated by counting the initial and final numbers of fish and the number of daily moratalities. At the beginning and end of the experiment, the total length of 30 individual fish was measured and the results were statistically subjected to a significance test ( $t$-test).

The final remaining fish were sampled and analyzed for mositure, lipid classes, and fatty acid compositions. The data in the tables and diagrams indicate the mean value of the duplicate experiments.

2. Red sea bream (Expt. II). Larval fish of $10.3 \pm 0.6 \mathrm{~mm}$ in total length, which had been reared with S-type rotifers fed on Nannochloropsis and omega-yeast ${ }^{3)}$ and with minced fish, were randomly divided into eight groups (duplicate experiments) containing 200 fish each in $100 \mathrm{l}$ polycarbonate tanks. They were fed respectively with one of four varieties of Artemia for 14 days at a water temperature of $24.3-26.7^{\circ} \mathrm{C}$. Seawater and aeration were supplied at $600 \mathrm{ml} / \mathrm{min}$ and $400 \mathrm{~m} / / \mathrm{min}$, respectively. The feeding rate ranged between $(2-10) \times 10^{5}$ nauplii/tank per day. At the end of the trial 50 fish were subjected to an activity test by holding them out of the water in a scoop net for $30 \mathrm{~s}$, transferring them into a $30 /$ tank, keeping them there for $24 \mathrm{~h}$ to check the fish's response to the stress. Calculations of survival rate, fish sampling, and analytical items were all as described in Expt. I.

\section{Results and Discussion}

\section{Lipid Composition of Artemia in Expts. I and II}

Moisture, lipid contents, lipid classes, and fatty acid compositions of Artemia enriched with various types of oil for 19-24 h are shown in Table 1. During the experimental period the

Table 1. Moisture, lipid content, lipid classes, ${ }^{* 1}$ and $n-3 H U F A^{* 2}$ contents in Artemia nauplii enriched with various types of oil for $19-24 \mathrm{~h}$ in Expts. I and II

\begin{tabular}{|c|c|c|c|c|c|c|c|c|c|c|}
\hline & \multicolumn{5}{|c|}{ Experiment I } & \multicolumn{5}{|c|}{ Experiment II } \\
\hline & No & TG & $\mathrm{ME}$ & $\mathrm{EE}$ & FFA & Initial & No & TG & $\mathrm{ME}$ & $\mathrm{EE}$ \\
\hline Moisture (\%) & 91.0 & 90.4 & 90.1 & 89.6 & 89.5 & 82.0 & 88.8 & 86.9 & 86.7 & 86.3 \\
\hline \multicolumn{11}{|c|}{ (Dry weight, $\%$ ) } \\
\hline Total lipid & 28.5 & 33.3 & 33.4 & 35.5 & 20.9 & 26.3 & 21.8 & 35.3 & 35.7 & 36.7 \\
\hline Polar lipid & 20.2 & 16.8 & 15.9 & 15.8 & 12.1 & 15.5 & 16.9 & 18.1 & 20.6 & 20.4 \\
\hline TG & 1.5 & 10.2 & 10.6 & 12.1 & 1.4 & 5.3 & 1.3 & 13.8 & 11.3 & 13.0 \\
\hline FFA & 5.2 & 3.8 & 4.2 & 4.8 & 5.7 & 3.4 & 2.3 & 1.6 & 1.9 & 1.6 \\
\hline FS & & & & & & 0.3 & 0.7 & 0.5 & 0.5 & 0.4 \\
\hline DG & 1.6 & 2.5 & 2.7 & 2.8 & 1.6 & 1.0 & 0.3 & 0.9 & 1.0 & 0.9 \\
\hline MG & & & & & & 0.7 & 0.2 & 0.3 & 0.2 & 0.3 \\
\hline n-3HUFA & 1.3 & 4.1 & 5.3 & 5.4 & 1.7 & 0.9 & 1.0 & 6.5 & 6.4 & 7.1 \\
\hline $\mathrm{EPA}^{* 2}$ & 1.1 & 3.2 & 4.1 & 4.2 & 1.5 & 0.7 & 0.8 & 4.7 & 4.9 & 5.4 \\
\hline DHA*2 & ND & 0.4 & 0.7 & 0.6 & 0.1 & ND & ND & 1.2 & 0.9 & 1.1 \\
\hline
\end{tabular}


nauplii fed on various types of oil except for the emulsified FFA were found to incorporate lipids effectively by the direct method. The contents of lipid, TG, and n-3HUFA in Artemia fed on emulsified TG, ME, and EE were high compared to those without treatment or those fed on emulsified FFA. In particular, the highest n-3HUFA content was observed in Artemia fed on emulsified EE. On the other hand, the FFA content was high in Artemia without enrichment or those fed on emulsified FFA. These results were almost the same as in the previous experiment. ${ }^{2)}$

Feeding of Larval Fish with Artemia in Expts. I and II

The results of 10 days' feeding of Japanese striped knifejaw and 14 days' feeding of red sea bream are shown in Table 2. Similar feeding results were obtained in both Expts. I and II. Larval striped knifejaw fed on nauplii enriched with TG, ME, and EE, which were high in the amount of n-3HUFA, ranging from 4.1 to $5.4 \%$, showed good results in growth, survival, and activity tests. On the other hand, in the fish fed on nauplii without emulsified oil (the intact nauplii), containing a low amount of n-3HUFA, growth, survival rates and survival after the activity test were low. The fish fed on FFAenriched Artemia containing $1.7 \%{ }^{* 1}$ n-3HUFA also showed poor feed performances. A significant difference was observed in the total length of fish between those fed on nauplii enriched with TG, ME, and EE, and those fed on nauplii without treatment or with FFA. In red sea bream, growth and survival rates and survival after the
Table 2. Growth, survival rates, and survival rate after activity test in larval striped knifejaw after 10-day feeding and in larval red sea bream after 14-day feeding

$(\%)$

\begin{tabular}{|c|c|c|c|}
\hline Tank no. & $\begin{array}{l}\text { Final total } \\
\text { length }(\mathrm{mm})\end{array}$ & $\begin{array}{l}\text { Survival } \\
\text { rate }\end{array}$ & Activity*1 \\
\hline \multicolumn{4}{|c|}{ Striped knifejaw (Expt. I) ${ }^{* 2}$} \\
\hline $1(\mathrm{No})^{* 3}$ & $17.6 \pm 1.9 \mathrm{a} * 4$ & 62.3 & 7 \\
\hline $2(\mathrm{TG})$ & $18.6 \pm 1.8^{\mathrm{b}}$ & 99.8 & 99 \\
\hline $3(\mathrm{ME})$ & $18.4 \pm 2.4^{b}$ & 98.3 & 100 \\
\hline $4(\mathrm{EE})$ & $18.5 \pm 2.5^{b}$ & 99.0 & 100 \\
\hline 5 (FFA) & $17.4 \pm 1.8^{a}$ & 84.9 & 15 \\
\hline \multicolumn{4}{|c|}{ Red sea bream (Expt. II)*j } \\
\hline $6(\mathrm{No})$ & $21.6 \pm 1.6^{\mathrm{a}}$ & 94.4 & 3 \\
\hline $7(\mathrm{TG})$ & $23.9 \pm 1.7^{\mathrm{b}}$ & 98.5 & 100 \\
\hline $8(\mathrm{ME})$ & $23.9 \pm 1.7^{\mathrm{b}}$ & 97.8 & 100 \\
\hline $9(\mathrm{EE})$ & $23.7 \pm 1.4^{b}$ & 97.0 & 100 \\
\hline
\end{tabular}

*1 Survival rate after activity test.

*2 Initial total length: $10.1 \pm 0.8$ (Mean \pm S.D. $n=30$ ).

* See Table 1.

*4 Means with different superscripts are significantly different $(P<0.05$, Expt. I; $P<0.01$, Expt. II.).

*s Initial total length: $10.3 \pm 0.6$ (Mean \pm S.D. $₫=30$ ).

activity test were all high in fish fed on nauplii emulsified with TG, ME, and EE. These nauplii contained 6.4 to $7.1 \%{ }^{* 1} \mathrm{n}$-3HUFA. On the other hand, the fish fed on nauplii without emulsifjed oil, which contained $1.0 \%$ n-3HUFA but no docosahexaenoic acid (DHA), showed a high survival rate, but quite low activity. These results are in agreement with the recent report that larval red sea bream require at least $0.5-1 \%{ }^{* 1}$ of DHA in Artemia to obtain a high activity value. ${ }^{43, * 2}$ It has also been demonstrated that DHA is found to be superior to eicosapentaenoic acid (EPA) as EFA for many marine larval and ju-

Table 3. Moisture, lipid content, and lipid classes* of larval striped knifejaw and red sea bream fed on Artemia nauplii enriched with various types of oil in Expts. I and II

\begin{tabular}{|c|c|c|c|c|c|c|c|c|c|c|c|}
\hline & \multicolumn{6}{|c|}{ Striped knifejaw (Expt. I) } & \multicolumn{5}{|c|}{ Red sea bream (Expt. II) } \\
\hline & Initial & No & TG & ME & $\mathrm{EE}$ & FFA & Initial & No & TG & $\mathrm{ME}$ & $\mathrm{EE}$ \\
\hline Moisture $(\%)$ & 84.0 & 81.4 & 81.6 & $\begin{array}{c}81.6 \\
\text { (Dry }\end{array}$ & $\begin{array}{l}81.5 \\
\text { weight }\end{array}$ & $\begin{array}{l}81.2 \\
\%)\end{array}$ & 82.5 & 81.6 & 79.8 & 79.7 & 79.5 \\
\hline Total lipid & 13.2 & 12.8 & 14.4 & 16.7 & 18.2 & 11.4 & 15.4 & 11.0 & 18.9 & 19.6 & 21.0 \\
\hline Polar lipid & 7.5 & 6.3 & 6.5 & 6.7 & 7.1 & 5.9 & 7.2 & 5.7 & 5.8 & 6.0 & 6.0 \\
\hline TG & 0.3 & 0.6 & 1.3 & 2.5 & 3.3 & 0.3 & 0.4 & 0.6 & 7.5 & 8.9 & 10.2 \\
\hline FFA & 2.0 & 2.6 & 3.3 & 4.2 & 4.4 & 2.6 & 3.6 & 1.6 & 2.7 & 2.2 & 2.3 \\
\hline FS & 2.9 & 2.5 & 2.6 & 2.5 & 2.6 & 1.8 & 3.0 & 2.5 & 1.9 & 1.6 & 1.8 \\
\hline $\mathrm{DG}$ & 0.2 & 0.3 & 0.3 & 0.4 & 0.4 & 0.1 & 0.4 & 0.2 & 0.5 & 0.4 & 0.4 \\
\hline $\mathrm{MG}$ & 0.1 & 0.2 & 0.1 & 0.2 & 0.1 & 0.1 & 0.5 & 0.1 & 0.3 & 0.2 & 0.2 \\
\hline
\end{tabular}

* See the footnote to Table 1 .

*1 Dry matter basis.

*2 T. Takeuchi, M. Toyota, and T. Watanabe: Oral presentation at the annual meeting of Japan. Soc. Sci. Fish., in Tokyo, April 1991, p. 38. 


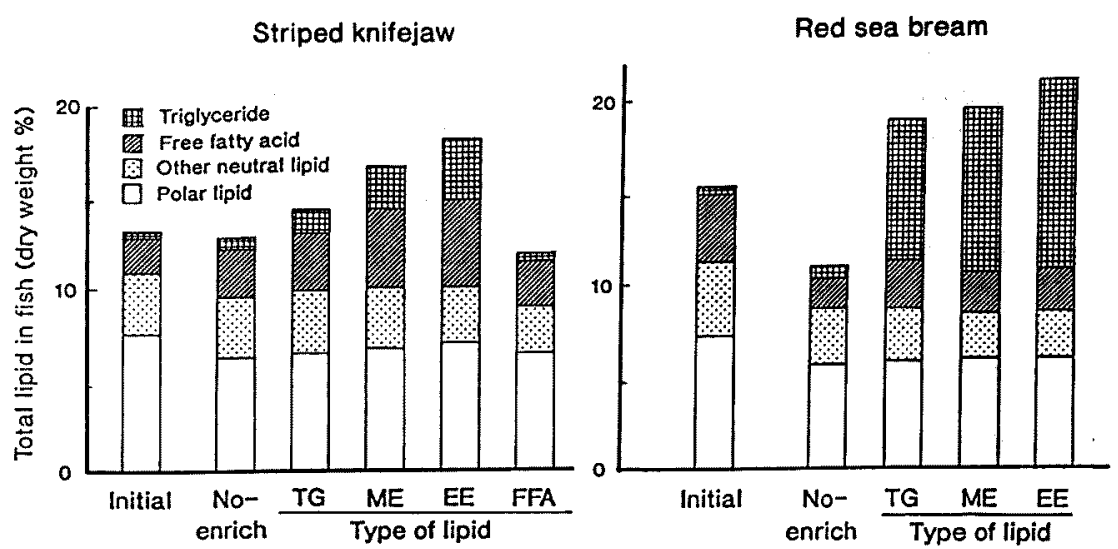

Fig. 1. Lipid classes of larval striped knifejaw and red sea bream fed on Artemia nauplii enriched with various types of oil.

Table 4. Fatty acid composition of neutral and polar lipids in larval striped knifejaw fed on Artemia nauplii enriched with various types of oil in Expt. I

(area $\%$ )

\begin{tabular}{|c|c|c|c|c|c|c|c|c|c|c|c|c|}
\hline \multirow{3}{*}{ Fatty acid } & \multicolumn{6}{|c|}{ Neutral lipid } & \multicolumn{6}{|c|}{ Polar lipid } \\
\hline & \multirow[b]{2}{*}{ Initial } & \multicolumn{5}{|c|}{ Tank no. } & \multirow[b]{2}{*}{ Initial } & \multicolumn{5}{|c|}{ Tank no. } \\
\hline & & $\begin{array}{c}1 \\
\text { (No) }\end{array}$ & $\begin{array}{c}2 \\
(\mathrm{TG})\end{array}$ & $\begin{array}{c}3 \\
(\mathrm{ME})\end{array}$ & $\begin{array}{c}4 \\
(E E)\end{array}$ & $\begin{array}{c}5 \\
\text { (FFA) }\end{array}$ & & $\begin{array}{c}1 \\
\text { (No) }\end{array}$ & $\begin{array}{c}2 \\
\text { (TG) }\end{array}$ & $\begin{array}{c}3 \\
(\mathrm{ME})\end{array}$ & $\begin{array}{c}4 \\
(E E)\end{array}$ & $\begin{array}{c}5 \\
\text { (FFA) }\end{array}$ \\
\hline $14: 0$ & 2.4 & 1.0 & 1.5 & 1.4 & 1.5 & 1.1 & 1.0 & 0.5 & 0.5 & 0.5 & 0.5 & 0.5 \\
\hline $15: 0$ & 0.6 & 0.2 & 0.2 & 0.2 & 0.2 & 0.2 & 0.7 & 0.2 & 0.3 & 0.3 & 0.2 & 0.2 \\
\hline $16: 0$ & 16.2 & 12.4 & 12.0 & 12.0 & 12.0 & 12.1 & 23.6 & 17.4 & 21.7 & 22.1 & 21.0 & 21.4 \\
\hline $16: \ln -7$ & 11.4 & 4.2 & 5.1 & 5.7 & 5.8 & 4.0 & 5.1 & 3.0 & 2.8 & 2.8 & 2.8 & 2.9 \\
\hline $17: 0$ & 1.1 & 0.8 & 0.7 & 0.7 & 0.7 & 0.7 & 1.5 & 0.8 & 1.0 & 0.9 & 0.9 & 1.1 \\
\hline $16: 3 n-6$ & 0.8 & 1.0 & 0.9 & 1.0 & 0.9 & 0.9 & 0.7 & 0.8 & 1.0 & 1.0 & 0.9 & 0.7 \\
\hline $18: 0$ & 6.7 & 8.4 & 7.0 & 6.4 & 6.6 & 7.6 & 11.2 & 9.9 & 9.9 & 9.8 & 9.8 & 11.7 \\
\hline $18: \ln -(9+7)$ & 14.7 & 31.7 & 27.6 & 27.5 & 28.9 & 26.6 & 17.5 & 26.0 & 22.6 & 21.6 & 22.0 & 25.5 \\
\hline $18: 2 n-6$ & 5.5 & 6.0 & 4.7 & 4.7 & 4.6 & 6.1 & 3.7 & 7.8 & 4.4 & 3.7 & 3.8 & 6.0 \\
\hline $18: 3 n-6$ & 0.3 & 0.4 & 0.3 & 0.3 & 0.3 & 0.3 & 0.1 & 0.3 & 0.2 & 0.2 & 0.1 & 0.2 \\
\hline $18: 3 n-3$ & 2.3 & 16.4 & 12.5 & 12.7 & 12.0 & 14.0 & 1.1 & 11.9 & 5.4 & 4.5 & 4.5 & 7.2 \\
\hline $18: 4 n-3$ & 0.4 & 1.5 & 1.2 & 1.4 & 1.3 & 1.1 & tr & 0.6 & 0.3 & 0.2 & 0.3 & 0.3 \\
\hline $20: 0$ & $\operatorname{tr}$ & 0.2 & 0.1 & 0.1 & 0.1 & 0.2 & 0.2 & 0.2 & 0.2 & 0.2 & 0.2 & 0.2 \\
\hline $20: 1$ & 0.7 & 1.4 & 1.3 & 1.4 & 1.2 & 0.9 & 0.8 & 1.0 & 0.8 & 0.7 & 0.8 & 0.8 \\
\hline $20: 2 n-6$ & 0.1 & 0.2 & 0.2 & 0.2 & 0.2 & 0.2 & 0.3 & 0.4 & 0.3 & 0.2 & 0.2 & 0.3 \\
\hline $20: 3 n-6$ & 0.3 & 0.2 & 0.1 & 0.1 & 0.1 & 0.2 & 0.3 & 0.2 & 0.1 & 0.1 & 0.1 & 0.2 \\
\hline $20: 4 n-6$ & 6.6 & 2.6 & 2.7 & 2.3 & 2.2 & 3.7 & 3.8 & 2.7 & 2.4 & 2.4 & 2.4 & 2.2 \\
\hline $20: 3 n-3$ & $\operatorname{tr}$ & 0.6 & 0.4 & 0.3 & 0.4 & 0.5 & 0.1 & 0.6 & 0.3 & 0.3 & 0.3 & 0.6 \\
\hline $20: 4 n-3$ & 0.9 & 0.8 & 0.6 & 0.6 & 0.7 & 0.7 & 0.4 & 0.8 & 0.4 & 0.4 & 0.4 & 0.5 \\
\hline $20: 5 n-3$ & 16.5 & 5.5 & 11.0 & 11.2 & 11.0 & 11.6 & 9.2 & 7.8 & 11.0 & 11.2 & 11.9 & 6.7 \\
\hline $22: 1$ & 0.1 & 0.4 & 0.2 & 0.3 & 0.3 & 0.3 & tr & 0.2 & 0.1 & 0.1 & 0.1 & 0.2 \\
\hline $22: 4 n-6$ & 0.6 & 0.5 & 0.4 & 0.3 & 0.2 & 0.5 & 0.4 & 0.4 & 0.3 & 0.3 & 0.2 & 0.5 \\
\hline $22: 5 n-6$ & $\operatorname{tr}$ & $\operatorname{tr}$ & $\operatorname{tr}$ & $\operatorname{tr}$ & $\operatorname{tr}$ & $\operatorname{tr}$ & $\operatorname{tr}$ & $\operatorname{tr}$ & 0.1 & 0.1 & 0.1 & 0.1 \\
\hline $22: 5 n-3$ & 4.3 & 0.5 & 2.1 & 2.0 & 2.0 & 1.7 & 6.2 & 1.4 & 3.2 & 3.1 & 3.2 & 2.0 \\
\hline $22: 6 n-3$ & 3.9 & 0.4 & 4.2 & 4.0 & 4.1 & 2.3 & 6.0 & 1.0 & 7.9 & 8.8 & 9.2 & 2.2 \\
\hline$\Sigma$ Saturates & 27.3 & 23.0 & 21.6 & 20.9 & 21.2 & 21.8 & 38.3 & 29.0 & 33.6 & 33.7 & 32.6 & 35.3 \\
\hline$\Sigma$ Monoenes & 26.9 & 37.9 & 34.4 & 34.9 & 36.2 & 31.9 & 23.5 & 30.1 & 26.4 & 25.2 & 25.8 & 29.5 \\
\hline$\sum \mathrm{n}-6$ & 14.1 & 10.9 & 9.3 & 8.8 & 8.5 & 12.0 & 9.2 & 12.7 & 8.8 & 7.9 & 7.8 & 10.4 \\
\hline$\sum n-3$ & 28.4 & 25.6 & 32.0 & 32.2 & 31.4 & 31.8 & 23.0 & 24.2 & 28.5 & 28.5 & 29.8 & 19.4 \\
\hline$\sum$ n-3HUFA & 25.7 & 7.8 & 18.3 & 18.2 & 18.1 & 16.7 & 21.9 & 11.6 & 22.9 & 23.8 & 25.0 & 12.0 \\
\hline
\end{tabular}


venile fish. ${ }^{5-7), * 1,2}$

\section{Lipid Composition of Larval Fish}

Moisture, lipid content, and lipid classes of larval striped knifejaw and red sea bream fed on Artemia nauplii enriched with various types of oil in Expts. I and II are shown in Table 3 and Fig.
1. The terminal fish given each Artemia in Expts. I and II showed low moisture in their bodies compared to those of the initial fish. The fish fed on nauplii without enrichment or enriched with emulsified FFA showed a low content of total lipid due to the decrease of TG, while it was increased in the fish fed on emulsified TG, ME,

Table 5. Fatty acid composition of neutral and polar lipids in larval red sea bream fed on Artemia nauplii enriched with various types of oil in Expt. II

(area $\%$ )

\begin{tabular}{|c|c|c|c|c|c|c|c|c|c|c|}
\hline \multirow{3}{*}{ Fatty acid } & \multicolumn{5}{|c|}{ Neutral lipid } & \multicolumn{5}{|c|}{ Polar lipid } \\
\hline & \multirow[b]{2}{*}{ Initial } & \multicolumn{4}{|c|}{ Tank no. } & \multirow[b]{2}{*}{ Initial } & \multicolumn{4}{|c|}{ Tank no. } \\
\hline & & $\begin{array}{c}6 \\
\text { (No) }\end{array}$ & $\begin{array}{c}7 \\
(T G)\end{array}$ & $\begin{array}{c}8 \\
(\mathrm{ME})\end{array}$ & $\begin{array}{c}9 \\
(\mathrm{EE})\end{array}$ & & $\begin{array}{c}6 \\
(\mathrm{No})\end{array}$ & $\begin{array}{c}7 \\
\text { (TG) }\end{array}$ & $\begin{array}{c}8 \\
(\mathrm{ME}) \\
\end{array}$ & $\begin{array}{c}9 \\
(\mathrm{EE})\end{array}$ \\
\hline $14: 0$ & 0.8 & 1.1 & 1.5 & 1.2 & 1.4 & 0.5 & 0.4 & 0.5 & 0.5 & 0.5 \\
\hline $14: 1$ & 0.8 & 0.6 & 0.5 & 0.4 & 0.5 & 0.3 & 0.2 & 0.1 & 0.1 & 0.1 \\
\hline $15: 0$ & 0.4 & 0.3 & 0.3 & 0.2 & 0.2 & 0.4 & 0.2 & 0.2 & 0.2 & 0.2 \\
\hline $16: 0$ & 9.9 & 13.5 & 11.4 & 11.3 & 11.6 & 18.5 & 19.2 & 20.8 & 21.7 & 21.6 \\
\hline $16: \ln -7$ & 10.4 & 3.0 & 4.7 & 4.6 & 5.0 & 4.4 & 1.4 & 1.5 & 1.5 & 1.6 \\
\hline $17: 0$ & 1.2 & 0.8 & 1.0 & 0.9 & 1.0 & 1.4 & 0.9 & 0.8 & 0.8 & 0.8 \\
\hline $16: 3 n-6$ & 1.5 & 1.1 & 0.9 & 0.8 & 0.8 & 0.9 & 0.7 & 0.5 & 0.5 & 0.4 \\
\hline $16: 3 n-3$ & 0.2 & 0.1 & 0.2 & 0.2 & 0.2 & 1.1 & 2.3 & 1.4 & 1.3 & 1.4 \\
\hline $18: 0$ & 5.8 & 5.3 & 4.9 & 5.0 & 4.8 & 10.0 & 10.8 & 9.7 & 10.1 & 10.0 \\
\hline $18: \ln -9$ & 13.4 & 18.7 & 20.1 & 20.3 & 19.7 & 11.3 & 17.8 & 13.8 & 13.8 & 13.5 \\
\hline $18: 1 n-7$ & 10.6 & 7.4 & 7.0 & 7.0 & 6.8 & 8.1 & 6.5 & 5.5 & 5.4 & 5.4 \\
\hline $18: 2 n-9$ & $\operatorname{tr}$ & 0.1 & 0.1 & 0.1 & 0.1 & $\mathrm{tr}$ & 0.2 & 0.2 & 0.1 & 0.1 \\
\hline $18: 2 \mathrm{n}-6$ & 4.1 & 8.3 & 5.3 & 5.2 & 5.1 & 2.3 & 7.0 & 3.2 & 2.9 & 2.7 \\
\hline $18: 3 n-6$ & 0.3 & 0.4 & 0.3 & 0.3 & 0.3 & 0.3 & 0.3 & 0.2 & 0.2 & 0.2 \\
\hline $18: 3 n-3$ & 3.2 & 18.3 & 14.6 & 14.3 & 14.1 & 1.1 & 9.1 & 3.9 & 3.6 & 3.4 \\
\hline $18: 4 n-3$ & 0.4 & 1.2 & 1.7 & 1.6 & 1.7 & $\operatorname{tr}$ & 0.4 & 0.2 & 0.2 & 0.2 \\
\hline $20: 0$ & 0.2 & 0.1 & 0.2 & 0.2 & 0.2 & 0.2 & 0.2 & 0.2 & 0.2 & 0.2 \\
\hline $20: 1$ & 0.8 & 0.9 & 1.5 & 1.5 & 1.6 & 0.5 & 1.2 & 1.2 & 1.1 & 1.2 \\
\hline $20: 2 n-6$ & 0.1 & 0.3 & 0.2 & 0.2 & 0.2 & 0.1 & 0.4 & 0.2 & 0.2 & 0.2 \\
\hline $20: 3 n-6$ & 0.1 & 0.3 & 0.1 & 0.1 & 0.1 & 0.1 & 0.3 & 0.1 & 0.1 & 0.1 \\
\hline $20: 4 n-6$ & 4.0 & 3.1 & 1.3 & 1.4 & 1.4 & 3.2 & 2.9 & 2.4 & 2.2 & 2.1 \\
\hline $20: 3 n-3$ & 0.1 & 1.0 & 0.5 & 0.5 & 0.5 & 0.1 & 1.1 & 0.4 & 0.4 & 0.4 \\
\hline $20: 4 n-3$ & 1.0 & 1.0 & 0.8 & 0.9 & 0.9 & 0.5 & 0.9 & 0.4 & 0.4 & 0.4 \\
\hline $20: 5 n-3$ & 14.9 & 7.3 & 10.5 & 11.2 & 11.7 & 9.3 & 6.6 & 10.5 & 10.0 & 10.0 \\
\hline 22: 0 & 0.1 & 0.1 & 0.2 & 0.2 & 0.1 & 0.1 & 0.2 & 0.1 & 0.1 & 0.1 \\
\hline $22: 1$ & 0.3 & 0.1 & 0.3 & 0.3 & 0.2 & 0.1 & 0.1 & 0.1 & tr & tr \\
\hline $22: 4 n-6$ & 0.8 & tr & $\operatorname{tr}$ & $\operatorname{tr}$ & tr & 0.8 & 0.1 & 0.1 & 0.1 & 0.2 \\
\hline $22: 5 n-6$ & 0.2 & $\operatorname{tr}$ & $\operatorname{tr}$ & tr & tr & 0.3 & $\operatorname{tr}$ & 0.3 & 0.2 & 0.2 \\
\hline $22: 5 n-3$ & 1.7 & 0.5 & 1.8 & 1.9 & 1.9 & 2.8 & 1.6 & 3.5 & 3.5 & 3.7 \\
\hline $22: 6 n-3$ & 8.3 & 0.7 & 3.7 & 3.8 & 3.5 & 17.2 & 2.6 & 14.1 & 14.7 & 14.9 \\
\hline$\sum$ Saturates & 18.4 & 21.3 & 19.4 & 19.1 & 19.4 & 31.2 & 32.0 & 32.3 & 33.6 & 33.5 \\
\hline$\Sigma$ Monoenes & 36.4 & 32.3 & 35.1 & 35.2 & 34.9 & 24.9 & 27.9 & 23.0 & 22.7 & 22.4 \\
\hline$\sum n-6$ & 11.1 & 13.4 & 8.2 & 8.1 & 12.9 & 8.1 & 11.7 & 6.9 & 6.5 & 6.1 \\
\hline$\Sigma \mathrm{n}-3$ & 29.8 & 30.2 & 33.8 & 34.4 & 34.4 & 32.1 & 24.6 & 34.5 & 34.2 & 34.3 \\
\hline$\sum \mathrm{n}$-3HUFA & 26.0 & 10.6 & 17.3 & 18.3 & 18.4 & 29.9 & 12.8 & 29.0 & 29.0 & 29.3 \\
\hline
\end{tabular}

*1 A. Kanazawa, S. Kobayashi, S. Teshima, and S. Koshio: Oral presentation at the annual meeting of Japan. Soc. Sci. Fish, in Tokyo, April 1989, p. 48.

*2 M. Toyota, T. Takeuchi, T. Watanabe, F. Fujimoto, and K. Imaizumi: Oral presentation at the annual meeting of Japan. Soc. Sci. Fish., in Tokyo, April 1991, p. 38. 
Striped knifejaw

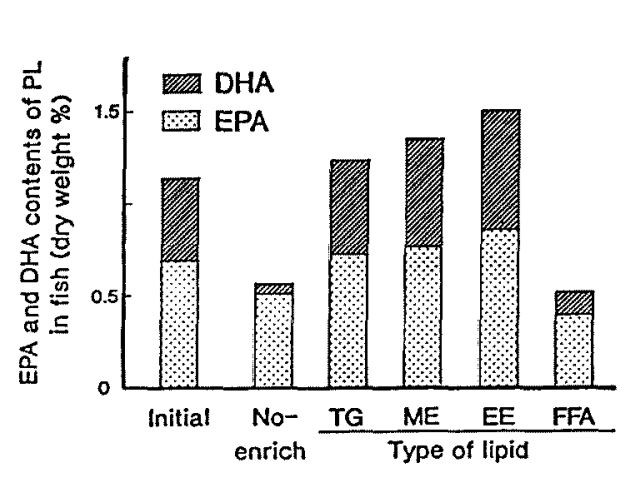

Red sea bream

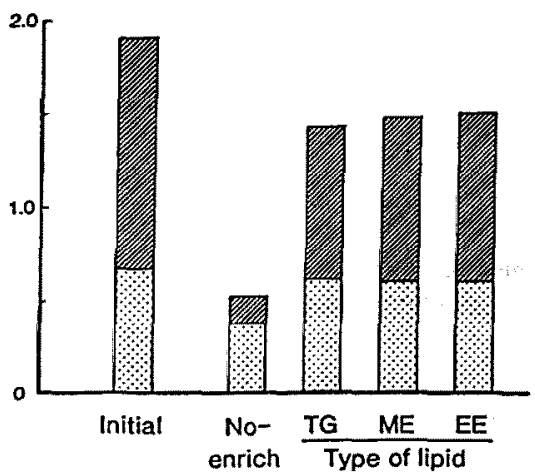

Fig. 2. EPA and DHA contents in the polar lipid from larval striped knifejaw and red sea bream fed on Artemia nauplii enriched with various types of oil.

and EE (Fig. 1). In particular, the highest contents of total lipid and TG were observed in fish fed on EE-enriched Artemia. Namely, the lipid content of larval fish was clearly reflected by that of Artemia. There was no marked difference in the polar lipid content and other neutral lipids between the treatments in Expts. I and II.

Fatty Acid Composition of Polar and Nonpolar Lipid Fractions in Larval Fish

The fatty acid compositions of polar and nonpolar lipid fractions from whole bodies of Japanese striped knifejaw and red sea bream are shown in Tables 4 and 5, respectively. The EPA and DHA contents of PL in fish are also illustrated in Fig. 2. The terminal fish given nauplii with various treatments in Expts. I and II showed high percentages of linolenic acid (18: $3 n-3)$ in polar and neutral lipid fractions of whole bodies compared to those of the initial fish. This result was due to the high amount of 18 : $3 n-3$ in the experimental nauplii, which is called the freshwater type. ${ }^{8)}$ EPA plus DHA contents of PL in fish fed on nauplii without treatment or those enriched with emulsified FFA in both experiments were quite low compared to those fed on nauplii with emulsified TG, ME, and EE (Fig. 2). Especially, the DHA content was markedly different between both the groups. This result agrees with the poor feed performances in fish fed on FFA-enriched nauplii containing an insufficient amount of n-3HUFA to satisfy the EFA requirement. In both the striped knifejaw and red sea bream, the maximum EPA plus DHA content was recorded for the fish fed on EE-enriched Artemia. The percentage of EPA was almost the same between polar and neutral lipid fractions in both Expts. I and II.

On the other hand, the percentage of DHA was much lower in nonpolar lipid fraction. It has been observed that the percentage of DHA in whole body neutral lipid markedly decreases compared with that of polar lipid, when larval and juvenile fish are fed on a diet containing low content of n-3HUFA or DHA. ${ }^{45}$ Consequently, the amount of DHA in Artemia enriched with TG, ME, and EE in this experiment might not be sufficient for larval fish, even though larval fish showed good feed performances. Further experiments are needed to clarify the requirement of marine larval fish for DHA in Artemia.

From the former experiment, in which the n3HUFA content of Artemia was high when EEtype oil was used for enrichment, and also from present observations, it may be concluded that the dietary value of nauplii for larval striped knifejaw and red sea bream is effectively improved by feeding the nauplii with the emulsion of an ester oil, particularly the ethyl ester type. On the other hand, it is also found that poor growth performance of fish fed on nauplii enriched with emulsified FFA was induced by poor incorporation of n-3HUFA into the nauplii due to coagulation of the FFA.

\section{Acknowledgements}

The authors express here their sincere thanks to Nagasaki Prefectural Institute of Fisheries for its kind assistance in the feeding experiments and to Nippon Suisan Kaisha Ltd. for preparation of the four types of oil containing $43 \% \mathrm{n}-3$ HUFA. 
The present work was supported in part by a Grant for Scientific Research (C) from The Ministry of Education, Science, and Culture and " in part by research funds from Marino-Forum 21.

\section{References}

1) A. Kanazawa, S. Koshio, and S. Teshima: Growth and survival of larval red sea bream Pagrus major and Japanese flounder Paralichthys olivaceus fed microbound diets. $J$. World Aquacult. Soc., 20, 31-37 (1989).

2) T. Takeuchi, M. Toyota, and T. Watanabe: Comparison of lipid and n-3 highly unsaturated fatty acid incorporations between Artemia enriched with various types of oil by the direct method, Nippon Suisan Gakkaishi, 59, 277-281 (1992).

3) O. Imada, Y. Kageyama, T. Watanabe, C. Kitajima, S. Fujita, and $Y$. Yone: Development of a new yeast as a culture medium for living feeds used in the production of fish seed. Nippon Suisan Gakkaishi, 45, 955-959 (1979).

4) M. S. Izquierdo, T. Watanabe, T. Takeuchi, T. Arakawa, and
C. Kitajima: Optimal EFA levels in Artemia to meet the EFA requirements of red sea bream (Pagrus major). Proc. Third Int. Symp. on Feeding and Nutr. in Fish., Toba, Aug. 28-Sept. 1, Japan, 1989, pp. 221-232.

5) T. Watanabe, T. Arakawa, T. Takeuchi, and S. Satoh: Comparison between eicosapentaenoic and docosahexaenoic acids in terms of essential fatty acid efficiency in juvenile striped jack Pseudocaranx dentex. Nippon Suisan Gakkaishi, 55, 1989-1995 (1989).

6) T. Watanabe, M. S. Izquierdo, T. Takeuchi, S. Satoh, and C. Kitajima: Comparison between eicosapentaenoic and docosahexaenoic acids in terms of essential fatty acid efficacy in larval red seabream. Nippon Suisan Gakkaishi, 55, 16351640 (1989).

7) T. Takeuchi, M. Toyota, S. Satoh, and T. Watanabe: Requirement of juvenile red seabream Pagrus major for eicosapentaenoic and docosahexaenoic acids. Nippon Suisan Gakkaishi, 56, 1263-1269 (1990).

8) T. Watanabe, F. Oowa, C. Kitajima, and S. Fujita: Relationship between the dietary value of brine shrimp Artemia salina and their content of $\omega 3$ highly unsaturated fatty acids. Nippon Suisan Gakkaishi, 46, 35-41 (1980). 